\title{
Ambulance personnel and critical incidents
}

\author{
Impact of accident and emergency work on mental health \\ and emotional well-being
}

DAVID A. ALEXANDER and SUSAN KLEIN

Background The association between mental health and occupational factors among ambulance personnel has not been thoroughly investigated in the UK.

\begin{abstract}
Aims To identify the prevalence of psychopathology among ambulance personnel and its relationship to personality and exposure to critical incidents.
\end{abstract}

\begin{abstract}
Method Data were gathered from ambulance personnel by means of an anonymous questionnaire and standardised measures.
\end{abstract}

Results Approximately a third of the sample reported high levels of general psychopathology, burnout and posttraumatic symptoms. Burnout was associated with less job satisfaction, longer time in service, less recovery time between incidents, and more frequent exposure to incidents. Burnout and GHQ-28 caseness were more likely in those who had experienced a particularly disturbing incident in the previous 6 months. Concerns about confidentiality and career prospects deter staff from seeking personal help.

\section{Conclusions The mental health and} emotional well-being of ambulance personnel appear to be compromised by accident and emergency work.

\section{Declaration of interest Grant} received from the Chief Scientist Office of the Scottish Office Home and Health Department.
The physical and emotional welfare of the workforce is an important issue (Secretary of State for Health, 1992), and particular concerns have been expressed about high levels of physical and mental symptoms and 'burnout' among health care workers (e.g. Ramirez et al, 1996; Guthrie et al, 1999). Ambulance personnel in the UK display higher rates of early retirement on the grounds of mental and physical ill health than other health care staff (Rodgers, 1998), but the possible association between work demands and health has not been rigorously investigated in this group. In their surveys of ambulance personnel, Rodgers (1998) and James \& Wright (1991) alluded to the potentially deleterious effect of exposure to 'critical incidents' on the health of ambulance personnel, but did not investigate it. (A critical incident may be defined as an incident that is sufficiently disturbing to overwhelm or threaten to overwhelm the individual's usual method of coping.) It is commonly asserted that emergency personnel have a more 'hardy' personality, but they can be vulnerable to severe and chronic post-traumatic psychopathology following major disasters (e.g. Duckworth, 1986). This study addresses two questions: (a) what is the association between regular exposure to critical incidents and mental and emotional welfare in a Scottish ambulance service, and (b) does 'hardiness' offer protection against the effects of regular exposure to such incidents?

\section{METHOD}

\section{Subjects}

All 160 personnel carrying out accident and emergency duties for a Scottish regional ambulance service were invited to contribute to this anonymous survey. The sample did not include staff whose duties were confined to administration or patient transport.
There was extensive early consultation with prospective subjects; personal visits to 14 of the 16 ambulance stations were made by the researchers, notices about the study were distributed widely throughout the service, and the support of trade union officials was enlisted in an effort to obtain a good response rate.

\section{Measures}

General psychopathology was assessed by means of the 28-item General Health Questionnaire (GHQ-28; Goldberg \& Hillier, 1979). Suitable for identifying minor psychiatric disorder in community samples, this measure allows caseness to be determined by means of the total score. For this survey, scores of 5 and above were used to identify 'cases' with maximal sensitivity and specificity (Goldberg \& Williams, 1988).

The Impact of Event Scale (IES; Horowitz et al, 1979) was used to determine the frequency of the self-reported post-traumatic symptoms of avoidance behaviour and intrusive events (e.g. flashbacks and nightmares) in relation to a specific critical incident (nominated by the subject). This measure was therefore given only to those subjects who reported having experienced a personally disturbing incident in the previous 6 months. The subjects' total scores were classified according to the scheme recommended by the scale authors: 'low' (0-8), 'medium' (9-19) and 'high' $(20+)$.

'Burnout' was assessed by the Maslach Burnout Inventory (MBI; Maslach \& Jackson, 1986). This measures the cumulative effects of work-related pressures on three states: 'depersonalisation', 'emotional exhaustion' and 'personal accomplishment'. The first state refers to a loss of concern and compassion towards others. The second state describes a condition of being overextended and emotionally drained. The third state reflects the subject's sense of personal achievement at work. High scores for the first two scales and low scores for the last one are associated with burnout. The classification of 'low', 'moderate', and 'high' is achieved by cut-off scores described by Maslach $\&$ Jackson.

The 45 -item version of the Hardiness Scale (HS), devised by Bartone et al (1989), measures three traits of 'hardiness': 'commitment', 'control' and 'challenge'. According to Maddi \& Kobasa (1984), 
these traits shield the individual against the impact of potentially disturbing events. Those with a 'hardy' personality view such events as being under their control ('control'), as a challenge rather than as a threat ('challenge'), and as meaningful rather than as random or pointless ('commitment'). Subjects were classified as either 'high' or 'low' in terms of hardiness according to the scoring scheme described by Bartone et al (1989).

To indicate the employees' level of satisfaction with the internal features of their accident and emergency work, they completed the Job Satisfaction sub-scale (JSs) of the Pressure Management Indicator (PMI; Williams \& Cooper, 1996). The Organisational Satisfaction sub-scale (OSs) of this questionnaire was also used to provide a measure of the employees' level of satisfaction with the external features of their organisation. For both sub-scales we used the scoring system recommended by these authors, in which high scores indicate high levels of satisfaction.

The methods these staff used to cope with the most disturbing incident they had experienced in the previous 6 months were recorded by means of the Coping Methods Checklist (CMC; Alexander \& Wells, 1991). This eight-item list identifies which methods were used and with what degree of self-reported success. If the subjects had used a particular method they were asked to endorse it as 'very helpful', 'helpful', 'not sure', 'unhelpful' or 'very unhelpful'.

In addition to the measures described above, based on consultation and a pilot study, a questionnaire was designed to obtain additional information including age, years of operational experience, the features of the most disturbing critical incident encountered in the previous 6 months, the effect of regular exposure to critical incidents, and the perceived value of support, coping methods, training and equipment.

All measures were reproduced in a single printed booklet which was distributed to 160 potential subjects through the internal mailing system of the ambulance service. After completion, the booklets were returned anonymously directly to the researchers using the stamped, addressed envelope provided.

\section{Statistical analysis}

The software SPSS for Windows (version 6.1) was used to input and analyse the data.
Non-parametric methods were used in the face of skewed distributions and heterogeneity of variance.

\section{RESULTS}

\section{Response rates}

Of the 160 ambulance personnel, 110 $(69 \%)$ returned completed questionnaire booklets. This figure represents 40 paramedics and 70 ambulance technicians. There were 15 women (14\%) and 95 men $(86 \%)$. The median length of operational service was 9 years, with a range of 1-30 years. The distribution of banded age was: 20-29 years, $n=19$ (17\%); 30-39 years, $n=52(47 \%) ; 40-49$ years, $n=24(22 \%)$, and 50 years or more, $n=15(14 \%)$.

Overall, $90(82 \%)$ of the respondents had experienced a particularly disturbing incident in the previous 6 months. These individuals were compared with those who had not experienced an incident to identify any differences in their demographic profile. Chi-squared analyses revealed that there were no significant differences between these two groups in terms of age $\left(\chi^{2}=0.22\right.$, d.f. $\left.=1, P=0.63\right)$, whether they were paramedics or technicians $\left(\chi^{2}=1.57\right.$, d.f. $\left.=1, P=0.21\right)$, and length of service $\left(\chi^{2}=0.14, \quad\right.$ d.f. $=1$, $P=0.70$ ).

\section{Psychopathology and burnout}

For the total sample of $\mathbf{1 1 0}$ respondents the mean score on the GHQ-28 was 3.9 and the standard deviation was 5.2. Scores for the three sub-scales of the MBI were 'depersonalisation', mean 8.4, s.d. 6.7; 'emotional exhaustion', mean 17.2, s.d. 10.7, and 'personal accomplishment' mean 34.5 , s.d. 7.8 .

Caseness on the GHQ-28 was recorded in 35 subjects $(32 \%)$, and on the MBI the numbers in the 'high' category for depersonalisation and emotional exhaustion were $29(26 \%)$ and $22(20 \%)$ respectively. The figure for 'low' personal accomplishment was 40 (36\%).

Analyses by Spearman's rank correlation indicated that GHQ-28 scores were unrelated to the number of years' experience $\left(r_{s}=-0.014, P=0.88\right)$ as were the MBI sub-scales of depersonalisation $\left(r_{s}=-0.04, \quad P=0.69\right) \quad$ and emotional exhaustion $\left(r_{s}=0.12, P=0.13\right)$. On the other hand, personal accomplishment did correlate negatively with years of experience $\left(r_{s}=-0.29, P=0.002\right)$. (The negative direction of the correlation indicates that a greater sense of accomplishment is significantly associated with a shorter length of service.)

Table 1 displays the number of respondents identified as cases by the GHQ-28 and those who fell into the 'high' category on each of the three sub-scales of the MBI, according to whether or not the subjects had experienced a personally disturbing incident in the preceding 6 months. The final two columns report the results of the chi-squared analyses for these two samples.

Scores on the emotional exhaustion sub-scale had a low but significant positive correlation with the number of critical incidents experienced in the previous 6 months $\left(r_{s}=0.25, P=0.02\right)$. Also, those with high emotional exhaustion scores were significantly more likely to report that they 'never' had enough time to recover between such incidents $(z=-2.15, P=0.03)$, as were those with a lower sense of personal accomplishment $(z=-2.01, P=0.05)$.

\section{Post-traumatic symptoms}

Only the 90 respondents who had experienced a personally disturbing incident in the previous 6 months completed the IES. The severity of their symptoms (as indicated by their total IES scores) was classified as 'low' in $36(40 \%)$, 'medium' in 27 $(30 \%)$ and 'high' in $27(30 \%)$. The means (and standard deviations) for intrusion, avoidance and total scores were, respectively, 7.8 (8.3), 7.7 (8.1) and 15.5 (15.7).

The duration of distress following a particularly disturbing incident was as follows: a few hours (7 respondents) about 1 day (10), a few days (31), about 1 week (14), a few weeks (16), about 1 month (1), a few months (2) and longer (5).

\section{Frequency and type of incidents}

Figure 1 displays the frequency with which the ambulance personnel attended different categories of incident in the previous 6 months and the proportion thereof which were regarded by them as 'personally disturbing'. Although self-harm and suicide are the most common incidents, road traffic accidents and medical emergencies are the most disturbing ones. Open text comments revealed that the following features, either in combination or individually, were the most likely to be identified with the 'most disturbing' incidents:

(a) a child victim; 
Table I The association of GHQ-28 caseness and high burnout in ambulance workers related to the experience of a personally disturbing incident (PDI) in the preceding 6 months

\begin{tabular}{|c|c|c|c|c|c|c|}
\hline & \multicolumn{2}{|c|}{ Experienced PDI } & \multicolumn{2}{|c|}{ Not experienced PDI } & \multirow[t]{2}{*}{$\chi^{2}$} & \multirow[t]{2}{*}{$P$} \\
\hline & $\%$ & $n$ & $\%$ & $n$ & & \\
\hline GHQ-28 caseness & 37 & $33 / 90$ & 10 & $2 / 20$ & 5.36 & 0.021 \\
\hline \multicolumn{7}{|l|}{ MBI sub-scales: } \\
\hline Depersonalisation & 32 & $29 / 90$ & 0 & $0 / 20$ & 8.75 & 0.003 \\
\hline Emotional exhaustion & 23 & $21 / 90$ & 5 & $I / 20$ & - & $0.064^{\prime}$ \\
\hline Personal accomplishment & 33 & $30 / 90$ & 35 & $7 / 20$ & 0.02 & 0.891 \\
\hline
\end{tabular}

GHQ-28, 28-item General Health Questionnaire; MBI, Maslach Burnout Inventory.

I. Fisher's exact test.

(b) the victim is known to the ambulance crew (not uncommon in rural areas);

(c) the ambulance crew feel helpless at the scene;

(d) particularly severe injuries;

(e) lack of prompt back-up from colleagues;

(f) the ambulance crew are given false information about the site of the accident or the condition of the victim(s).

Moreover, 62 of these subjects $(69 \%)$ reported that they 'never' had sufficient time to recover emotionally between critical incidents. Open text comments confirmed that many respondents felt the control room despatchers did not use enough discretion or sensitivity in relation to which crews they sent to certain incidents.

\section{Exposure to and coping with critical incidents}

Forty-four of 89 subjects (49\%) reported that the more frequent their exposure to critical incidents the better they coped with them, whereas $2(2 \%)$ felt that they coped less well. Thirty-four $(38 \%)$ considered that their ability to cope was not affected by frequent exposure. However, the remaining 9 subjects who responded $(10 \%)$ felt that although they initially coped better with such incidents, subsequently they found it more difficult to cope.

\section{Support}

After critical incidents peers were regarded as either 'always' or 'frequently' supportive by 40 of the 90 subjects $(44 \%)$, whereas senior colleagues were considered to be as supportive by only $6(7 \%)$ of them. Moreover, $66(73 \%)$ of this group judged the ambulance service in general to be 'never' concerned about staff welfare after disturbing incidents.

\section{Confidentiality and career prospects}

Concerns about confidentiality and risk to career prospects were identified as being
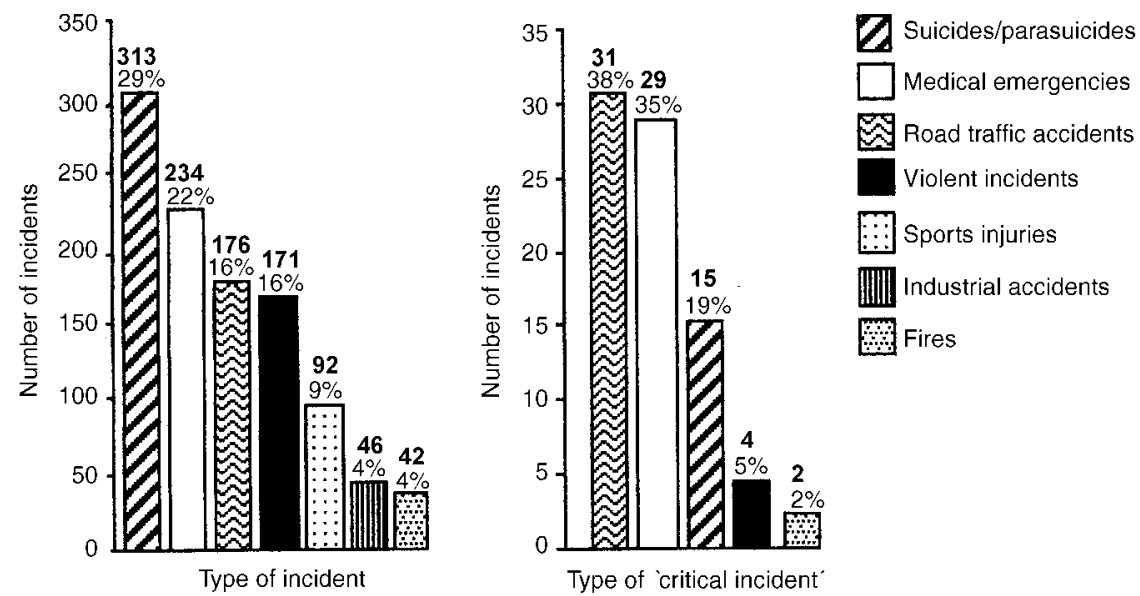

Fig. I Number of incidents attended and those deemed critical.

either 'always' or at least 'frequently' deterrents to seeking personal help after such incidents by $58(64 \%)$ and 41 (46\%) respectively of the 90 ambulance personnel who had encountered a disturbing incident in the previous 6 months.

\section{Training, pre-incident briefing and equipment}

Over a third of the staff claimed that better training $(38 \%)$ and better pre-incident briefing $(36 \%)$ would have helped them to cope more successfully with previous critical incidents. Only 8 out of $88(9 \%)$ held this view for equipment (some individuals did not reply to this item).

\section{Coping methods}

Table 2 lists the methods of coping used by staff who had experienced a particularly disturbing incident in the previous 6 months, and how helpful they were found to be.

\section{Hardiness}

Of the three sub-scales of the Hardiness Scale, only the 'commitment' sub-scale was found to have a significant association with the IES, the MBI and the GHQ-28 (Table 3). The 'control' sub-scale had an association with the GHQ-28 and all three MBI sub-scales. The MBI sub-scales of 'emotional exhaustion' and 'personal accomplishment' were found to have a significant association with the 'challenge' sub-scale of the HS. Overall, therefore, those with a 'hardy' personality display significantly less burnout than those with a less 'hardy' one.

\section{Job satisfaction}

The mean score on the Job Satisfaction subscale was 23.7 with a standard deviation of 5.2. Eighty-nine of the sample $(81 \%)$ were identified as having a 'high' level of satisfaction (as indicated by a score of 20 and above). The JSs scores were negatively related to scores on the MBI sub-scales of 'emotional exhaustion' $\left(r_{s}=-0.36\right.$, $P<0.001)$ and 'depersonalisation' $\left(r_{s}=-0.31, \quad P=0.001\right)$. The 'personal accomplishment' sub-scale had a positive correlation with the JSs $\left(r_{\mathrm{s}}=0.33\right.$, $P=0.001)$. 
Table 2 Methods of coping with the most disturbing incident experienced in the previous 6 months

\begin{tabular}{|c|c|c|c|c|c|c|c|c|c|c|}
\hline \multirow[t]{2}{*}{ Method of coping } & \multicolumn{2}{|c|}{ Used } & \multicolumn{2}{|c|}{ Very helpful } & \multicolumn{2}{|c|}{ Helpful } & \multicolumn{2}{|c|}{ Unhelpful } & \multicolumn{2}{|c|}{ Very unhelpfu } \\
\hline & $\%$ & $n$ & $\%$ & $n$ & $\%$ & $n$ & $\%$ & $n$ & $\%$ & $n$ \\
\hline Black humour & 7I & 64 & 25 & 16 & 59 & 38 & 14 & 9 & 2 & I \\
\hline Talking with colleagues & 94 & 85 & 49 & 42 & 47 & 40 & 4 & 3 & 0 & 0 \\
\hline Looking forward to off-duty & 92 & 83 & 53 & 44 & 35 & 29 & II & 9 & 1 & I \\
\hline Keeping thoughts/feelings to self & 82 & 74 & 7 & 5 & 22 & 16 & 59 & 44 & 12 & 9 \\
\hline Thinking about own family & 83 & 75 & 31 & 23 & 45 & 34 & 19 & 14 & 5 & 4 \\
\hline Thinking about outside interests & 70 & 62 & 29 & 18 & 60 & 37 & II & 7 & 0 & 0 \\
\hline $\begin{array}{l}\text { Thinking about positive } \\
\text { benefits of work }\end{array}$ & 29 & 25 & 34 & 25 & 39 & 29 & 23 & 17 & 4 & 3 \\
\hline $\begin{array}{l}\text { Avoid thinking about what } \\
\text { you are doing }\end{array}$ & 69 & 61 & 13 & 8 & 28 & 17 & 52 & 32 & 7 & 4 \\
\hline
\end{tabular}

\section{Organisational satisfaction}

The mean score on the Organisational Satisfaction sub-scale was 14.5 with a standard deviation of 5.3. Thirty-nine respondents $(35 \%)$ fell into the 'high' category for organisational satisfaction (as indicated by a score of 17 or above). The OSs scores were negatively correlated with scores on two sub-scales of the MBI: 'depersonalisation' $\left(r_{s}=-0.31, P=0.001\right)$ and 'emotional exhaustion' $\left(r_{s}=-0.29, P=0.002\right)$.

\section{DISCUSSION}

This first-ever survey of a Scottish ambulance service raises important concerns about the relationship between work and mental health. More specifically, it informs the current debate about the impact of 'critical incidents' on emotional wellbeing - an issue that has recently attracted considerable attention.

\section{Job satisfaction}

The least surprising finding is the high level of reported job satisfaction. Earlier surveys of ambulance personnel (e.g. James \& Wright, 1991) and of other health care staff (e.g. Payne \& Firth-Cozens, 1987; Ramirez et al, 1996) have indicated that providing care for others is personally gratifying. However, the distinction between satisfaction with the internal features of a job ('job satisfaction') and satisfaction with the way a system operates ('organisational satisfaction') needs to be upheld. Clearly, these subjects were more satisfied with the former than with the latter. Moreover, complacency by any organisation concerned about the well-being of its employees. This satisfaction may be purchased at a price: a price to be measured in terms of the levels of general psychopathology, burnout and post-traumatic symptoms, as displayed by this sample. The overall level of caseness on the expressed job satisfaction does not justify

Table 3 Hardiness and its relationship to the IES, the MBI and the GHQ-28

\begin{tabular}{|c|c|c|c|c|c|c|}
\hline & \multicolumn{6}{|c|}{ Hardiness Scale sub-scales } \\
\hline & \multicolumn{2}{|c|}{ Commitment } & \multicolumn{2}{|c|}{ Control } & \multicolumn{2}{|c|}{ Challenge } \\
\hline & $r_{\mathrm{s}}$ & $P$ & $r_{s}$ & $P$ & $r_{\mathrm{s}}$ & $P$ \\
\hline IES total score & -0.25 & 0.016 & -0.11 & 0.307 & -0.04 & 0.685 \\
\hline \multicolumn{7}{|l|}{ MBI sub-scales: } \\
\hline Depersonalisation & -0.45 & $<0.001$ & -0.27 & 0.004 & -0.15 & 0.122 \\
\hline Emotional exhaustion & -0.51 & $<0.001$ & -0.35 & $<0.001$ & -0.26 & 0.006 \\
\hline Personal accomplishment & 0.45 & $<0.001$ & 0.37 & $<0.001$ & 0.20 & 0.033 \\
\hline GHQ-28 total score & -0.18 & 0.056 & -0.23 & 0.016 & -0.08 & 0.413 \\
\hline
\end{tabular}

IES, Impact of Event Scale; MBI, Maslach Burnout Inventory; GHQ-28, 28-item General Health Questionnaire.

GHQ-28 was $32 \%$. This figure is markedly higher than the $18 \%$ to be found in the general population (Hardy et al, 1997). Moreover, it is considerably higher than the levels reported in other studies of health care workers. For example, Blenkin et al (1995) obtained a level of $21 \%$ in a crosssectional survey of 500 randomly selected National Health Service consultants in Scotland (using the same measure and cutoff point). Moreover, because of the culture of denial and suppressed emotions (which still pervades the emergency and caring services), these levels may underestimate the true prevalence of such phenomena.

\section{Role of experience}

These data challenge the oft-quoted assumption that 'it gets easier with experience'. For approximately $12 \%$ of this sample, additional experience of such incidents did not lead inevitably to an enhanced ability to cope with subsequent ones. Moreover, for the $10 \%$ for whom additional experience initially helped but subsequently made it more difficult to cope, the personal and managerial implications are important. Because they are experienced, such staff may be more reluctant than their less experienced colleagues to admit to having emotional difficulties. For the same reason, managerial staff may be less alert to their needs and to the early warning signs of problems among such staff.

Thus, the longer-term effect of this kind of work merits more attention; a point already made by Alexander \& Atcheson (1998) who noted, in a survey of nearly 300 nursing and medical staff in hospital trauma units, that it was the senior staff rather than the junior ones who were more likely to report emotional problems related to their trauma work. Also, Robinson (1993) in her study of Australian ambulance personnel concluded that cumulative stress was more common than stress from a single incident.

\section{Risk factors}

Why only some individuals report psychiatric and other emotional problems associated with their work is an important question which needs to be answered; possible causal factors need to be explored.

Certain incidents may be more 'psychonoxious' than others, and regular exposure to them may compromise the emotional well-being of staff. It is noteworthy that in 
this study ambulance staff who had experienced a particularly distressing incident in the previous 6 months had significantly higher levels of caseness on the GHQ-28 and higher scores on the 'depersonalisation' sub-scale of the MBI. Road traffic accidents and medical emergencies were most commonly identified as the most disturbing incidents-particularly if they involved child victims, if the victims were known to the ambulance personnel, if the injuries were particularly serious, or if the personnel experienced a sense of helplessness at the scene. Earlier studies have exposed the serious psychological impact of dealing with injured or dead children (e.g. James, 1988; Dyregrov \& Mitchell, 1992) and of the condition of helplessness in helpers and rescuers (Bryant \& Harvey, 1996) after major calamities.

The nature of the incident and its impact may also relate to the recovery time available before the ambulance crew have to deal with another critical incident. Over two-thirds of these subjects reported that there was insufficient time to recover between such events. No doubt such a circumstance will also increase their sense of overload, a factor identified by Ramirez et al (1996) as injurious to the emotional welfare of hospital consultants. While the ambulance service is a 'reactive' service, which therefore has to respond to a demand for help whatever it is, the control room despatchers do have some discretion as to which crew is sent to an incident - a discretion the subjects in this survey claim was not always exercised sensitively. The importance of recovery time is further underscored by the reported duration of some of the post-traumatic reactions. For some subjects, the effects of some events may endure for weeks or even months. The opportunity is therefore created for a cumulative effect. In view of the fact that depersonalisation refers to a lack of concern and compassion for others, this finding has obvious implications for the quality of a service provided for the general public.

\section{Support}

How colleagues react to those who have had a harrowing experience is widely recognised to have a bearing on how well they adjust (e.g. Taylor \& Frazer, 1982; Alexander \& Wells, 1991). This survey suggests that peer support is much more likely to be available than support from senior staff (although even with regard to peer support, less than half of the sample thought it was 'always' or 'frequently' available). What is even more striking is the fact that $73 \%$ viewed the ambulance service as 'never' concerned about staff welfare after critical incidents.

What underlies these claims this survey cannot determine. They may highlight an absence of a 'climate of care'. On the other hand, displacement may be involved; some staff may not be able to tolerate their own emotional vulnerability, and therefore they blame the system instead. Perhaps there is a communication problem among the different strata of staff such that the good intentions and concerns of senior staff are not recognised for what they are. Whatever the explanation for these observations, they pose a challenge to the service.

There also have to be concerns about the allegations that the crews are reluctant to seek help because of their anxieties about confidentiality and the perceived threat to their career prospects. Similar concerns have been noted in the other emergency services (Alexander, 1993).

\section{Training and preparation}

A number of studies have emphasised the psychoprophylactic value of good training and preparation for emotionally challenging duties (e.g. Meichenbaum \& Jaremko, 1983; Alexander, 1993; Dyregrov et al, 1996). About a third of respondents in this sample commented on the need for better training and pre-incident briefing. Certainly such matters are likely to reinforce the individual's sense of control when faced with difficult and challenging situations, and are likely to help in the development of effective coping strategies.

\section{Coping}

The research literature suggests that no single method of coping guarantees immunity from the malign effects of adversity. Rather, it is likely that the individual is best served by having a repertoire of methods which can be used flexibly and selectively.

The ambulance workers in this study showed a preference for talking over incidents with colleagues; almost all who used this method to cope with their most recent disturbing incident found it to be helpful, and almost half of them claimed that it was 'very helpful'. This choice is consistent with that shown by police officers in relation to work-related stress (Alexander \& Walker, 1994) and by nurses and doctors working in trauma units (Alexander \& Atcheson, 1998). Conversely, although over $80 \%$ kept their thoughts and feelings to themselves, a clear majority of them claimed this approach was unhelpful.

These findings highlight the need for staff to be available to support each other, and for the organisation to encourage and to facilitate this.

\section{Hardiness}

There has been an enthusiastic quest for variables that might moderate the negative effect of work on the health and well-being of employees. Hardiness has surfaced as one of the most popular concepts, and it has been researched in an increasingly varied number of work settings in relation to burnout (Schaufeli \& Enzmann, 1998). Because emergency workers are assumed to be hardier than most and because they reflect machismo ideals (James \& Wright, 1991), the Hardiness Scale is a particularly pertinent measure for studying this sample of ambulance personnel.

The data from this study add weight to the view that those with a 'hardy' personality are less likely to display general psychopathology, burnout and post-traumatic symptomatology (as measured by the GHQ-28, the MBI and the IES, respectively). However, the design of this study does not allow the determination of the role of the hardy traits. They may exert an effect in several ways, such as through an adaptive appraisal of events, or through the facilitation of other adaptive methods of coping such as exercise, diet and sleep. Similarly, this study cannot determine whether these qualities are immutable features of the personality or whether they can be developed through experience and training. The identification of personality features that serve to protect those who deliver health care against the rigours of their work also poses a dilemma, however, because these features may not necessarily be best suited to the delivery of that service. In a study of 170 junior house officers, it was the more empathic ones who were most emotionally distressed by the features of their work (Firth-Cozens, 1987). The challenge for a selection system based at least partly on personality features is to determine what strength of trait serves to protect individual workers and yet enables them to 
fulfil their health care role sensitively and compassionately.

\section{ACKNOWLEDGEMENTS}

Particular thanks to Mr J. Drummond (former Regional Director), Mr R. Gordon (Divisional Manager) and Mr A. Reid (Operations Officer) of the Scottish Ambulance Service. In addition, we appreciate the support of Dr A. Marsden (Consultant Medical Director) and Ms S. Rogers (Director of Personnel and Training), National Headquarters of the Scottish Ambulance Service.

The researchers are also indebted to the many ambulance personnel who gave up much time to contribute to this survey.

Dr S. Williams of Resource Systems generously allowed the survey to include the use of the Job Satisfaction and the Organisation Satisfaction subscales of the Pressure Management Indicator without charge.

Special thanks to Staff Nurse L. Bowes for her invaluable assistance in the collection of the data.

\section{REFERENCES}

Alexander, D. A. (1993) Stress among body handlers: a long-term follow-up. British Journal of Psychiatry, 163 806-808.

—\& Atcheson, S. F. (1998) Psychiatric aspects of trauma care: survey of nurses and doctors. Psychiatric Bulletin, 22, 132-136

_\& Walker, L. G. (1994) A study of methods used by Scottish police officers to cope with work-induced stress. Stress Medicine, 10, 131-138.

— \& Wells, A. (199I) Reactions of police officers to body-handling after a major disaster. A before-and-after comparison. British Journal of Psychiatry, I59, 547-555.

Bartone, P. T., Ursano, R. J., Wright, K. M., et al

(1989) The impact of a military air disaster on the health of ambulance workers: a prospective study. Journal of Nervous and Mental Disease, 177, 317-328.

Blenkin, H., Deary, I., Sadler, A., et al (1995) Stress in NHS consultants, British Medical Journal, 310, 534.

Bryant, R. A. \& Harvey, A. G. (1996) Post-traumatic stress reactions in volunteer fire fighters. Journal of Traumatic Stress, 9, 51-62.

Duckworth, D. H. (1986) Psychological problems arising from disaster work. Stress Medicine, 2, 315-323.

Dyregrov, A. \& Mitchell, J.T. (1992) Work with traumatized children - psychological effects and coping strategies. Journal of Traumatic Stress, 5, 5-17.

_ , Kristoffersen, J. I. \& Gjestad, R. (1996) Voluntary and professional disaster workers: similarities and differences in reactions. Journal of Traumatic Stress, $\mathbf{9}$ 54|-555.

Firth-Cozens, J. (1987) Emotional distress in junior house officers. British Medical Journal, 295, 533-536.

Goldberg, D. \& Hillier, V. F. (1979) A scaled version of the General Health Questionnaire. Psychological Medicine, 9, 139-145.

—\& Williams, P. (1988) A User's Guide to the General Health Questionnaire.Windsor: NFER-Nelson.

Guthrie, E., Tattan, T., Williams, E., et al (1999)

Sources of stress, psychological distress and burnout

\section{CLINICAL IMPLICATIONS}

- Accident and emergency work appears to exact a toll on the mental health and well-being of ambulance personnel.

- The ambulance service has a duty of care and needs to address these findings.

- Opportunities are identified in this survey for the ambulance service to adopt a prophylactic approach by reviewing its selection policy, the provision of support, and managerial practices.

\section{LIMITATIONS}

Because this is a cross-sectional study of one ambulance service, there are restrictions on how these data can be interpreted and on how far they can be generalised.

- Although over two-thirds of the subjects volunteered to contribute, there may have been some self-selection bias. (The anonymous design of the study precluded a comparison between respondents and non-respondents.)

- It would have been preferable to have had the results of the 28 -item General Health Questionnaire cross-validated against a structured clinical interview.

DAVID A. ALEXANDER, FBPS, SUSAN KLEIN, PhD, Department of Mental Health, Medical School, University of Aberdeen and Centre for Trauma Research, Royal Cornhill Hospital, Aberdeen, UK

Correspondence: Professor David A. Alexander, Department of Mental Health, Medical School, Foresterhill, Aberdeen AB25 2ZD,UK.E-mail: d.a.alexander@abdn.ac.uk

(First received 24 May 1999, final revision 13 June 2000, accepted 21 June 2000)

in psychiatrists. Comparison of junior doctors, senior registrars and consultants. Psychiatric Bulletin, 23 $207-212$

Hardy, G. E., Shapiro, D. A. \& Borrill, C. S. (1997) Fatigue in the workforce of national health service trusts: levels of symptomatology and links with minor psychiatric disorder, demographic, occupational and work role factors. Journal of Psychosomatic Research, 43 83-92.

Horowitz, M., Wilner, N. \& Alvarez, W. (1979) Impact of Event Scale: a measure of subjective stress Psychosomatic Medicine, 4I, 209-218.

James, A. (1988) Perceptions of stress in British ambulance personnel. Work Stress, 2, 319-326.

_ \& Wright, P. L. (1991) Occupational stress in the ambulance service. Journal of Managerial Psychology, $\mathbf{6}$ $13-22$

Maddi, S. R. \& Kobasa, S. C. (1984) The Hardy Executive: Health under Stress. Homewood, II: Dow Jones-Irwin

Maslach, C. \& Jackson, S. C. (1986) Maslach Burnout Inventory (2nd edn). Palo Alto: Consulting Psychologists Press.

Meichenbaum, D. \& Jaremko, M. E. (1983) Stress Reduction and Prevention. New York: Plenum.
Payne, R. \& Firth-Cozens, J. (1987) Stress in Health Professionals. Chichester: John Wiley \& Sons.

Ramirez, A. J., Graham, J., Richards, M. A., et al (1996) Mental health of hospital consultants: the effects of stress and satisfaction at work. Lancet, 347, 724-728.

Robinson, R. (1993) Follow-up Study of Health and Stress in Ambulance Services in Victoria, Australia. Victoria: Victorian Ambulance Crisis Counselling Unit.

Rodgers, L. M. (1998) A five year study comparing early retirements on medical grounds in ambulance personnel with those in other groups of health service staff. Part II: causes of retirements. Occupational Medicine, 48, 119-132.

Schaufeli, W. \& Enzmann, D. (1998) The Burnout Companion to Study and Practice: A Critical Analysis. London: Taylor \& Francis.

Secretary of State for Health (1992) The Health of the Nation. A Strategy for Health in England. London: HMSO.

Taylor, A. J.W. \& Frazer, A. G. (1982) The stress of post disaster body handling and victim identification work. Journal of Human Stress, 8, 4-12.

Williams, S. \& Cooper, C. L. (1996) Pressure Management Indicator. Harrogate: RAD. 